\title{
Reflexiones sobre la vida diplomática: actores, entramados y dinámicas. Perspectivas y propuestas a la luz de experiencias de investigación
}

\author{
Participan en esta sección: Marina Alvarado Cornejo, Pilar Cagiao Vila, \\ Paula Bruno, Ascensión Martínez Riaza y Alexandra Pita González
}

Paula Bruno (coordinadora)*

\section{INTRODUCCIÓN}

En la última década se revisaron varios aspectos sobre las dinámicas y los actores de la vida diplomática. Nuevas líneas historiográficas se trazaron al calor de las investigaciones y publicaciones de una amplia cantidad de especialistas provenientes de la Historia, la Antropología, los Estudios Internacionales, y las Ciencias Políticas. Algunos rasgos que distinguen estas nuevas producciones de la tradicional historia de la diplomacia y de los vínculos entre naciones son los siguientes: una actitud transdisciplinar - que habilita la utilización de cajas de herramientas variadas para estudiar redes, sociabilidades, trayectorias, y espacios de producción y circulación de saberes de proyección internacional-; apuestas interpretativas de articulación de escalas de análisis — nacional, regional, internacional— selección de objetos de estudio que, en sí mismos, habilitan una perspectiva trasnacional y atenta a superar los nacionalismos historiográficos. ${ }^{1}$

* Consejo Nacional de Investigaciones Científicas y Técnicas (CONICET), Universidad Torcuato di Tella, Buenos Aires, Argentina. Correo electrónico: pbruno@conicet.gov.ar ORCID: https://orcid.org/0000-0003-2877-617X

1 Pueden verse los siguientes dossiers para tener una aproximación a las posibilidades que se han abierto en los últimos años: "Relaciones internacionales, identidades colectivas y vida intelectual en América Latina, 1810-1945", coordinado por Ori Preuss y Juan Pablo Scarfi, publicado en Revista Complutense de Historia de América, núm. 39, 2013, contiene artículos de Paula Bruno, Charles Jones, João Paulo Coelho de Souza Rodrigues y Juan 
A la luz de estas nuevas líneas de investigación, en las intervenciones que se reúnen aquí pueden verse los aportes e interpretaciones que las investigadoras de dos proyectos afines han escrito a la hora de ser convocadas a pensar sobre algunas preguntas formuladas de manera deliberadamente amplia: ¿qué aportes tiene la perspectiva que has elegido para estudiar las relaciones entre vida cultural y diplomacia?, ¿en qué se diferencian —o asemejan — tus decisiones como investigadora respecto de líneas historiográficas más consolidadas -historia política, historia diplomática, historia cultural e intelectual一, ¿qué uso de las fuentes diplomáticas has concretado para abonar tus investigaciones?, ¿qué suma la mirada que has propuesto a consensos historiográficos vigentes?. ${ }^{2}$

Provenientes de distintas especialidades o campos de interés - historia intelectual y de los intelectuales, estudios culturales y literarios, historia de las migraciones, historia política, con varias declinaciones - y distintos espacios académicos y geografías (Argentina, Chile, México y España), como puede constatarse, compartimos algunas intuiciones. En estas reflexiones abundan sugerencias para pensar en distintas posibilidades a la hora de estudiar figuras, ámbitos, y procesos vinculados con la vida diplomática. Con estos ejercicios de reflexión acerca de las propias decisiones, opciones y preguntas, en estas intervenciones se explicitan algunas pistas metodológicas, preferencias, y alertas sobre potencialidades y límites de las perspectivas adoptadas. Quizás la

Pablo Scarfi; "Diplomacia, vida cultural y producción de saberes", coordinado por Juan Pablo Scarfi y publicado en los dossiers de difusión de historiapolitica.com bajo el número 66 en noviembre de 2015, contiene artículos de Martín Bergel, Paula Bruno, Álvaro Fernández Bravo, Pablo Ortemberg y Juan Pablo Scarfi; "Panamericanismo, hispanoamericanismo y nacionalismo en los festejos identitarios de América Latina, 1880-1920. Performances y encrucijadas de diplomáticos e intelectuales", coordinado por Pablo Ortemberg y publicado en Anuario IEHS, vol. 32, núm. 1, 2017, contiene artículos de Paula Bruno, Alexandra Pita González, Javier Moreno Luzón y Ascensión Martínez Riaza; "Intelectuales y diplomacia en América Latina", coordinado por Carlos Marichal y Alexandra Pita González en Revista de Historia de América, núm. 159, enero-junio de 2019, contiene artículos de Paula Bruno, Juan Pablo Scarfi, Nathalia Henrich, Mariana Moraes Medina y Cecilia Guadalupe Neubauer; "Reflexiones sobre el uso de fuentes diplomáticas para la reconstrucción histórica de la Argentina de la belle époque", coordinado por Martín Albornoz y Agustina Rayes, será publicado en un próximo número de Revista Electrónica de Fuentes y Archivos, contiene artículos de Martín Albornoz, Paula Bruno, Lila Caimari, Pablo Ortemberg y Agustina Rayes.

2 Se trata de los siguientes proyectos: "Entre la cultura y la diplomacia: intelectuales en América Latina entre las Independencias y la creación de la Organización de los Estados Americanos, 1810-1948" (HIST 02), financiado por el Instituto Panamericano de Geografía e Historia (IPGH), Organismo Especializado de la Organización de Estados Americanos (OEA), en el marco de los Proyectos Panamericanos de Asistencia Técnica 2020; y "España como escenario. Diplomacia y acción cultural en la formación de redes transnacionales con América, 1914-1945”, Ref. PGC2018-094231-B-100, financiado por el Ministerio de Ciencia, Innovación y Universidades de España en el marco de la Convocatoria 2018 de los Proyectos I+D Generación de Conocimiento. 
narración de estas experiencias colabora a que investigadores e investigadoras de nuevas generaciones descubran que los caminos para descubrir temas y objetos no siempre responden a un proceso lineal. En tanto recorridos sinuosos, están surcados, al menos en ocasiones, por encuentros fortuitos con fuentes, conversaciones azarosas, intereses, convicciones y presentimientos.

\section{Reflexión de Marina Alvarado Cornejo 3}

La diplomacia en Chile ha sido estudiada con asiduidad tanto desde la línea de los estudios históricos como desde el Derecho, convirtiéndose en el accionar de varones y, en menor medida, el de mujeres en la vida diplomática, en valiosa información para explicar acontecimientos, como conflictos bélicos, firma de tratados multilaterales, llegada e influencias de personalidades extranjeras al país, construcción de políticas nacionales e internacionales, construcción de redes intelectuales, entre otras.

La investigación sobre la diplomacia no se ha dado, sin embargo, en el ámbito de los estudios literarios y culturales, en las indagaciones chilenas se ha destacado la participación de escritores/as de la vida diplomática, como los ya paradigmáticos casos de Pablo Neruda, Gabriela Mistral y Amanda Labarca, esto no ha significado la apertura de una línea de estudios que dé cuenta de los alcances e implicancias que tuvieron las actividades internacionales de dichos autores/as para el desarrollo de las letras o bien de esferas aledañas, como la educativa.

Una segunda derivada de lo antes señalado, corresponde a la falta de estudios que se concentren en la labor de las mujeres en la diplomacia. Recientemente los trabajos de Alexandra Pita han venido a iluminar, desde la historia intelectual, lo que la poeta nortina realizó en pos de propiciar una opinión pública que impulsara la unión cultural, política y económica de los países Latinoamericanos, algo así como una cruzada bolivariana. ${ }^{4} \mathrm{Sin}$ embargo, Mistral sigue apareciendo como un caso aislado y excepcional, sin tener conocimiento sobre antecedentes previos de mujeres chilenas en la diplomacia.

Persiste, por tanto, una deuda no menor respecto de las mujeres involucradas directamente con labores diplomáticas tanto en los primeros cuarenta años del siglo XX como en la última parte del XIX, y, más aún, con aquellas mujeres

Correo electrónico: malvarado@ucsh.cl. ORCID: https://orcid.org/0000-0002-1206-6440

Pita González, Alexandra, "América (Latina) en París. Mistral, Reyes y Torres Bodet en la colección iberoamericana, 1927-1940”, en Fabián Herrera León y Yannick Wehrli (coords.), América Latina y el internacionalismo ginebrino de entreguerras: resonancias e implicaciones, México, Dirección General del Acervo Histórico Diplomático, 2019, pp. 241276. 
que, sin ser directamente las nombradas para realizar labores diplomáticas, tuvieron parte importante en esta área, ya fuera por vínculos familiares y/o personales. Así es como estas mujeres desarrollaron e impulsaron iniciativas de sumo valiosas, sin embargo, invisibilizadas, por ser consideradas actividades que respondían a acciones propias de la sociabilización "femenina", y no a proyectos culturales con repercusiones en la construcción del proyecto de nación, por ejemplo.

Tener como criterio de trabajo la distinción de los aportes de mujeres, ${ }^{5}$ hijas, esposas y hermanas de diplomáticos con la finalidad de reconocer y revalorizar sus aportes siguiendo la pista de las acciones desarrolladas gracias al capital social y relacional con el que contaban, permite ampliar las posibilidades de estudio del acontecer diplomático, por cuanto estas mujeres guían hacia actividades íntimas e incidentales que, incluso sin proponérselo, obtienen resultados diplomáticamente valiosos, a saber: exposiciones de arte; fundación de escuelas; invitaciones de personalidades extranjeras al país de origen de la "familia" diplomática; e instancias de socialización privada como las cenas, bailes o paseos. Por todo lo anterior, se proponen dos nociones clave para abordar esta propuesta de estudio: "intradiplomacia" y "oficio diplomático".

Las estrategias de socialización, legitimación y construcción de redes personales e individuales que conforman a la intradiplomacia y que serían desempeñadas por las mujeres en el espacio de lo privado, idóneas para su habitus género-sexual, traerían como resultado la transformación, a mediano y/o largo plazo, de campos específicos de la sociedad, puntualmente, el literario, el artístico y el educativo. Estos efectos son los que conformarían el oficio diplomático.

Fernando Reyes Matta explica que los escritores que han sido diplomáticos, como por ejemplo Octavio Paz, nunca experimentaron una escisión entre un rol y otro. Muy por el contrario, Reyes Matta señala a las misiones literarias y diplomáticas como un todo para los sujetos que ostentaron ambas actividades, debido a los intercambios culturales que las estancias en el extranjero les permitieron, y que de uno u otro modo fueron incorporadas en sus producciones escritas. Otro beneficio clave que el autor observa en este doble rol, es la

5 En la investigación que realicé anteriormente sobre la poeta chilena Teresa Wilms Montt, destaqué la importancia de los Balmaceda, su familia política, en la relación entre ella y sus hijas. De no haber sido porque sus suegros José Ramón Balmaceda y Sara Valdés Eastman tenían la tuición de sus hijas Sylva y Elisa, ella no habría podido verlas durante los últimos tres años de vida en París. Si bien este dato parece anecdótico, esto viene demostrar los espacios de circulación de las élites letradas chilenas de fines de siglo xIX e inicios del Xx, y las formas de sociabilización y circulación de las cuales disponían. Véase: Alvarado, Marina, Teresa Wilms Montt: estrategias textuales, conflictos de época, Santiago de Chile, Editorial Cuarto Propio, 2015. 
experiencia de intercambios e influencias, destacando el caso del escritor chileno Alberto Blest Gana, sobre quien relata:

Joven, aun militar, vive en París enviado a perfeccionarse, entre 1847 y 1851. Pero aquel es un periodo especialmente convulso y de debates, son los tiempos de la II República, de las protestas en la Comuna de París y de la crisis que llevará a Napoleón III al trono. Vive todo aquello mientras se entrega a fondo a la lectura de Balzac. Cuando regresa a Chile decide que lo suyo es la novela, pero con un enfoque muy concreto: inspirado en el naturalismo, quiere mostrar la realidad tal como es, con las costumbres que la gente vive en la calle. Es el costumbrismo, salpicado de giros chilenos en el lenguaje, lo que creía Blest Gana convertía este estilo en el medio más adecuado para difundir la literatura entre el pueblo. Su gran impacto popular llega en 1862 cuando se publica Martín Rivas. ${ }^{6}$

Junto a los aportes sindicados, recientemente he catastrado el positivo resultado que tuvo la misión de la escritora y profesora Amanda Labarca como invitada por el gobierno de Colombia, puntualmente por la Subsecretaría de Educación de dicho país. Ya que, junto con ser reconocida por el gobierno colombiano en 1936, ella permitió que libros de autores y autoras chilenos/ as llegaran a formar parte de la colección habitual de las bibliotecas del país cafetero. Ciertamente, conforme al documento "Partida de la Señora Amanda Labarca", la intelectual chilena dictó seis conferencias en el Teatro Municipal "con numerosa asistencia, especialmente de educadores, en las cuales estudió diversos aspectos del problema educativo tanto en Chile como en algunos países de Europa, Estados Unidos y México". ${ }^{7}$

Según se observa, los literatos asignados en misiones de esta naturaleza desplegaron acciones que superaron a las mismas tareas originalmente dispuestas. Los sucesos que experimentaron en el extranjero impulsaron su obra, a la vez que la mirada del país propio, pero desde "otro" sitio.

Bajo este contexto, entonces, la pregunta central a partir de la cual articulo mi propuesta indagatoria es la siguiente: ¿de qué modo el oficio diplomático de mujeres chilenas desde las últimas décadas de siglo XIX y las primeras del siglo $\mathrm{xx}$, vinculadas con la actividad cultural y literaria, movilizó el desarrollo de las principales esferas del campo cultural del país, a saber: la literatura, las artes y la educación? Afrontar el devenir de la diplomacia, mirando a sujetos antes no considerados más que como "consortes" del diplomático legal e institucionalmente establecido, es una perspectiva que permite complejizar lo que ya se conoce sobre la historia diplomática del país, dando cuenta de aquellas

6 Reyes Matta, Fernando. "Literatura, diplomacia y globalización”, Diplomacia, núm. 125, diciembre, 2012, p. 13.

7 Archivo Histórico, Ministerio de Relaciones Exteriores, Gobierno de Chile, "Partida de la Señora Amanda Labarca", 1936. 
acciones "privadas", pero cuyos resultados sobrepasaron la intimidad. Así también, permite reconstruir la genealogía de mujeres ligadas a la diplomacia, todo lo cual lleva a robustecer los méritos y trayectorias de las ya reconocidas diplomáticas Mistral y Labarca.

Es así como en una indagación en curso he considerado como punto de partida estudiar las trayectorias de Luisa Lynch (1862-1937), Eugenia Huici (1860-1951), Amalia Errázuriz (1860-1930), Carlina Rossi (1855-1919) y Carmen Bascuñán (1833-1911).

La decisión teórica y metodológica que guía esta propuesta para estudiar la diplomacia en Chile, dialoga directamente con la historia cultural e intelectual, la cual complementamos con la sociología de la cultura de Pierre Bourdieu, por cuanto interesa no sólo reconstruir el proceso, sino también indagar en la dinámica del mismo.

En vista que la propuesta de este estudio no ha sido profundizada, las fuentes documentales que se consideran para llevarlo a cabo son: cartas oficiales albergadas en fondo bibliográfico del Ministerio de Relaciones Exteriores; diarios de vida de las mujeres consideradas para el estudio; cartas personales entre miembros de las familias diplomáticas consideradas y actualmente publicadas; biografías; memorias de museos; memorias de escuelas; prensa cultural de la época, entre las principales.

En definitiva, la mirada que propongo no debe ser entendida como el estudio de la trastienda de la diplomacia, sino que, como la indagación de una parte relevante de la labor diplomática en su completitud, y cuyos resultados beneficiaron principalmente a las esferas literaria, artística y educativa, por cuanto las mujeres señaladas como parte de este estudio, tendieron puentes fundamentales entre Europa (continente donde estuvieron destinadas sus familias en misión diplomática) y Chile.

\section{Reflexión de Pilar Cagiao Vila ${ }^{8}$}

En verdad, llegué al asunto de las relaciones culturales y diplomáticas a través de otra de mis líneas de investigación: la de los movimientos migratorios. Andando ese camino, me topé con la iniciativa de un inmigrante gallego en Buenos Aires, Gumersindo Busto, quien, a la altura de 1904, pergeñó la idea de crear un fondo bibliográfico y museístico destinado a la universidad de su ciudad natal, Santiago de Compostela. Esa universidad —en la que adquirí parte de mi formación académica y donde desempeño mi actividad profesional desde hace más de tres décadas - recibió, entre aquella fecha y los años treinta, la generosa donación de ese personaje. Para llevar a cabo el extraordinario 
proyecto cultural, la Biblioteca América, contó con el esfuerzo colectivo de los inmigrantes españoles dispersos por el todo el continente americano y con el apoyo de amplios sectores de la vida pública e intelectual de sus diferentes países. A través del análisis de las relaciones personales e institucionales establecidas por su promotor, pude entender las motivaciones que impulsaron a unos y a otros a colaborar en un proyecto cultural que estuvo influenciado en su nacimiento y posterior evolución por corrientes ideológicas sumamente eclécticas que, sin embargo, tenían un denominador común: el fomento de las relaciones entre España y América.

La investigación llevada a cabo sobre ese fondo, con la ayuda de un equipo de investigadores entonces noveles, pero sumamente sagaces, me acercó a un riquísimo entramado de personajes, donantes y colaboradores del mismo que articularon una serie de redes extendidas por toda la geografía americana y que, en buena medida, traducían el estado intelectual americano de la primera mitad del siglo Xx. ${ }^{9}$ Muchos de ellos no eran sólo prohombres de la cultura o de la ciencia de cada uno de sus países, sino también diplomáticos, o ambas cosas a la vez. Todo ello me puso en la pista de que la Biblioteca América era mucho más que un fondo bibliográfico de valor indiscutible ya que, reconstruir su historia y conocer los avatares que la acompañaron, resultó fundamental para suscitar nuevas inquietudes encaradas a profundizar en las relaciones culturales entre España y América en el siglo xx y en la compleja realidad en la que se hallaban inmersas. Como quien reconstruye un rompecabezas del que, a día de hoy, me voy dando cuenta de todo encaja, esto implicaba abocarme, directa o indirectamente, al estudio y análisis de instituciones y de redes intelectuales a las que el quehacer diplomático no resultaba ajeno.

Fue así que me enamoré del tema de las relaciones entre vida cultural y diplomacia, ese enamoramiento, lejos de enfriarse, como ocurre a veces en las relaciones humanas, fue creciendo con el tiempo y me fue llevando por otros derroteros. El primero de ellos me condujo a aproximarme a otros ejemplos de acción cultural que, como la Biblioteca América, habían nacido en el nuevo marco de las relaciones entre España y América surgido en el tránsito del siglo XIX al XX no sólo en el conjunto del ámbito estatal español, sino también en el de los países americanos.

Surgieron así otros proyectos y otros equipos de investigación con los que compartí, y continúo compartiendo, inquietudes similares. Siempre, sin perder de vista que mi otro tema de investigación, el de las migraciones, resultaba también un campo abonado para el estudio de las relaciones diplomáticas y culturales, tanto de las formales - bilaterales entre países y protagonizadas por

9 Cagiao Vila, Pilar, "Los países americanos y la Biblioteca América: donantes, colaboradores y redes”, en Id. (coord.), Cien años de la Biblioteca América, 1904-2004, Santiago de Compostela, Servizo de Publicacións e Intercambio Científico USC, 2004, pp. 89-132. 
embajadores y cónsules - como de las informales. En este sentido, sobra decir, como subrayó en su día Carlos Rama en aquella obra pionera que fue casi un manual para quienes nos formamos en la década de los ochenta, ${ }^{10}$ que algunos emigrantes — particularmente los líderes étnicos_, ${ }^{11}$ como los intelectuales viajeros, cuya mirada siempre proporciona visiones de contraste respecto "al otro", 12 fueron verdaderos embajadores culturales al tiempo que testigos privilegiados de las relaciones entre España y América.

Desde el punto de vista cronológico, me interesé por momentos puntuales que significaron hitos determinantes de esas relaciones —en las que además de lo cultural se detecta casi siempre un trasfondo de interés económico-y que, por otro lado, a nivel internacional, coincidieron con el aumento creciente de contactos entre gobiernos, colectivos sociales e intercambios intelectuales entre ambos lados del Atlántico. La conmemoración del IV Centenario (1892); ${ }^{13}$ la fundación de grandes asociaciones y de otras más modestas entre las últimas décadas del siglo XIX y principios del xx; ${ }^{14}$ la celebración de los Centenarios de las Independencias; ${ }^{15}$ las convocatorias de diversos congresos y exposiciones internacionales o el vuelo Plus Ultra,${ }^{16}$ que junto con otras iniciativas formaron parte de mis intereses investigadores, traducen la intención de sectores del más variado tipo —oficiales y extraoficiales — de mejorar las relaciones entre España y los países americanos, no sólo en aras de una empatía diplomática,

Rama, Carlos, Historia de las relaciones culturales entre España y América Latina. Siglo XIX, México, Fondo de Cultura Económica, 1982.

11 Cagiao Vila, Pilar y Márquez Macías, Rosario, "Paraguay en el punto de mira de dos notables de la emigración española en el Río de la Plata", Boletín Americanista, núm. 73, Barcelona, 2016, pp. 55-73.

12 Cagiao Vila, Pilar, "Viajeros españoles en Argentina en el tiempo del Centenario", en Élida González Martínez y Ricardo González Leandri (eds.), Migraciones Trasatlánticas. Desplazamientos, etnicidad y políticas, Madrid, Los Libros de la Catarata, 2015, pp. 374395.

13 Cagiao Vila, Pilar, "Resonancias de un camino más allá de la política: el uruguayo Juan Zorrilla de San Martín y España”, en Pilar Cagiao Vila y J. Elías-Caro (comps.), España como escenario. Política y acción cultural de diplomáticos latinoamericanos (1880-1936), Ed. UniMagdalena, Santa Marta, 2018, pp. 51-86.

14 Cagiao Vila, Pilar, "El americanismo español en 1912: agenda, proyectos y preocupaciones", en XIX Jornadas de Historia de Ayamonte, Ayamonte, Servicio de Publicaciones Diputación de Huelva, pp. 85-98.

15 Cagiao Vila, Pilar, "Miradas españolas a las celebraciones de los centenarios de la independencia: así lo contó la prensa", en Pilar Cagiao Vila y J. M. Portillo Valdés (coords.), Entre Imperio y Naciones. Iberoamérica y el Caribe en torno a 1810, Santiago de Compostela, Servizo de Publicacións e Intercambio Científico, 2012, pp. 459-484.

16 Cagiao Vila, Pilar, "La "emoción de Montevideo": de la visita inesperada al homenaje oriental al Plus Ultra", en Rosario Márquez Macías (coord.), De Palos al Plata. El vuelo Plus Ultra a 90 años de su partida, Universidad Internacional de Andalucía, Sevilla, 2016, pp. 159-179. 
sino también por la existencia de una activa vida cultural en ambas orillas que, según los casos, revelaba sintonías y/o discrepancias. Todo ello al calor de las corrientes ideológicas imperantes en cada momento que dejaban sentir su influencia en los ambientes políticos y culturales de los diversos contextos analizados a lo largo de mis investigaciones.

Respecto a este último asunto, he de reconocer que el caso de las relaciones entre España y Uruguay fue siempre mi preferido. Mi tesis doctoral (que, como todas las tesis marca parte de la trayectoria investigadora) sobre las migraciones gallegas a esa orilla del Plata me permitió familiarizarme con los archivos uruguayos y documentarme ampliamente no sólo para aquel tema. Pero más que la tesis, fue quizás otro trabajo de hace tiempo el que me abrió las puertas al asunto particular de las relaciones diplomáticas y culturales entre ambos países. ${ }^{17}$ Desde entonces, y hasta el día de hoy en que me encuentro inmersa en la redacción de varios textos sobre el asunto durante el período de entreguerras, el Uruguay continúa ocupando el primer lugar de mis preferencias de investigación. Ello no quiere decir que, en otras oportunidades, no haya bosquejado en las relaciones diplomáticas y culturales de España con otros países americanos como Argentina, Colombia, Guatemala, Paraguay o Estados Unidos.

Desde un punto de vista metodológico, en más de una en ocasión me he inclinado por la investigación en trayectorias biográficas de determinados actores de la vida cultural y diplomática, cuyas experiencias vitales, incluso las de orden personal, resultaron claves para comprender las actuaciones públicas y privadas que desarrollaron en determinados contextos. Además, comparto la idea de que la prosopografía aporta elementos para la reconstrucción de redes y ofrece perspectivas de análisis para entender las motivaciones que impulsan los modos de actuar y de organizarse de quienes las componen. A la hora de establecer esas redes, los lazos personales y familiares resultan también de vital importancia, sobre todo para aquellos que necesitaron afianzarse política y profesionalmente. Todo ello permite, también, explicar el funcionamiento de los circuitos por los que transitaron trayectorias generacionales cruzadas y que, a su vez, dieron lugar - $\mathrm{O}$ no- a interaccionar en estructuras formales o informales (tertulias, asociaciones, instituciones, manifestaciones científicas y culturales, empresas editoriales y periodísticas...) de diferente grado de operatividad en las que se fueron desarrollando proyectos y actuaciones públicas y privadas que tuvieron mayor o menor impacto en las relaciones entre España y América.

17 Cagiao Vila, Pilar, "La imagen de España en América Latina: el caso uruguayo", en J. del Alcâzar y N. Tabanera, (coords.), Historia y presente en América Latina, Fundació Bancaixa,Valencia, 1996, pp. 205-236. 
Además, entre las diferentes posibilidades de análisis aplicadas a mis trabajos sobre los vínculos de la diplomacia y la vida cultural, he intentado penetrar en los engranajes de la actividad que, derivada de la función diplomática y consular, o de modo paralelo a ésta, desarrollaron algunos diplomáticos, cónsules y agentes culturales, atendiendo, por supuesto, al grado de proyección de su actividad según la centralidad de sus ubicaciones. Como suele ocurrir, la cuestión de la escala es siempre importante pues, evidentemente, no es lo mismo desempeñarse en una gran capital centro de poder que en el espacio reducido de una ciudad periférica, ${ }^{18}$ aunque, en ambos casos, las actuaciones particulares hayan podido derivar en otras de alcance bilateral o incluso transnacional en beneficio común o personal de los actores. ${ }^{19}$ Tampoco las cosas fueron iguales, por supuesto, para quienes no pertenecieron a la primera línea de la diplomacia o la cultura que para los que se encontraban en un rango superior. Para los primeros fue, si cabe, aún más importante gozar de unas relaciones personales apretadas que les permitieran ciertas cuotas de protagonismo, ${ }^{20}$ mientras que, para los segundos, la preeminencia de su cargo les permitía abrir las puertas de los ambientes culturales, aunque sus capacidades intelectuales no estuviesen a la altura requerida.

En todos los casos, y desde los planteamientos de la historia renovada de las relaciones diplomáticas y culturales, ha resultado fundamental, como no podía ser de otro modo, el manejo y cruce de fuentes de la más variada etiología (de archivos públicos y privados, españoles y americanos; colecciones hemerográficas; memorias e informes; literatura autobiográfica; epistolarios, iconografía) que me han permitido confrontar visiones y equilibrar subjetividades a la hora de aportar rigor y contribuir al conocimiento del vasto campo de las relaciones diplomáticas y culturales entre España y América.

\section{Reflexión de Paula Bruno ${ }^{21}$}

Mis intereses de investigación se concentraron en el estudio de biografías de intelectuales que desplegaron sus acciones en la segunda mitad del siglo

18 Cagiao Vila, Pilar y Márquez Macías, Rosario, "La Idea de América en el Club Palósfilo”, en Jangwa Pana, vol. 17, núm. 3, 2017, pp. 342-359.

19 Cagiao Vila, Pilar, "Matías Alonso Criado o la diplomacia transnacional", en Pilar Cagiao Vila (ed.), Donde la política no alcanza. El reto de diplomáticos, cónsules y agentes culturales en la renovación de las relaciones entre España y América, 1880-1939, IberoamericanaVervuert, Madrid-Frankfurt, pp. 19-71.

20 Cagiao Vila, Pilar y Márquez Macías, Rosario, "Veinte años de actividad diplomática y cultural del otro Gómez Carrillo (1903-1923)", en Pilar Cagiao Vila y Jorge Elías-Caro (comps.), España como escenario. Política y acción cultural de diplomáticos latinoamericanos (18801936), Ed. UniMagdalena, Santa Marta, 2018, pp. 115-166.

21 Correo electrónico: pbruno@conicet.gov.ar 
XIX y comienzos del siglo Xx. En un programa de investigación que lleva ya varios años, me detuve en trayectorias, espacios de sociabilidad y dinámicas de contacto entre mundos. Estudié también los ritmos y las formas en las que estos intelectuales intervinieron a la hora de pensar en la conformación de identidades -nacional, latinoamericana, hispanoamericana y antinorteamericana - con una marcada preferencia por revisar las figuras y las voces que, desde algunos consensos historiográficos, no eran representativas. Aposté por mostrar una pluralidad de voces que se configuraron en el fin de siglo argentino y las tensiones generadas en el marco de la construcción de ciertas modulaciones de la identidad nacional. Intenté mostrar hasta qué punto describir un clima de época homogéneo definido por rasgos generales y etiquetas, a priori efectivas, anula la posibilidad de desentrañar las dinámicas explícitas de un momento histórico, las confrontaciones y las fricciones. Analicé cómo rótulos que parecen contundentes para pensar una época - positivismo, por ejemplotienden a alisar superficies intelectuales de una vida cultural porosa. En suma, asumí el desafío de repensar consensos historiográficos y proponer que éstos no siempre son fotografías nítidas sobre las dinámicas del pasado histórico que nos interesa estudiar.

En mis contribuciones más recientes trabajé sobre la vida diplomática, las funciones estatales y las dinámicas culturales desplegados al calor de los procesos de consolidación de los estados nacionales en América Latina. ${ }^{22}$ A su vez, presté especial atención a lo que denomino "identidades en tensión" que tomaron fuerza en el giro del siglo XIX al XX —nacionalismo, latinoamericanismo, hispanoamericanismo, panamericanismo. Con estos objetivos me ocupé de interpelar líneas historiográficas consolidadas, pero que prácticamente no dialogan entre sí, como la historia de la conformación estatal y la invención de identidades nacionales, la historia diplomática y de los vínculos internacionales, la historia cultural y los estudios biográficos. Hasta el momento he trabajado en varios frentes que describo a continuación.

El primero apunta a pensar a los intelectuales argentinos en relación a universos o tramas de sentidos ofrecidos por los polos España, Estados Unidos y América Latina. Cada una de estas referencias geográficas está rodeada por repertorios de ideas y tensiones que emplazaron a las figuras argentinas a reflexionar e intervenir públicamente sobre problemas como los legados coloniales, la guerra de 1898 y la situación de Cuba, las discusiones limítrofes entre Argentina y Chile, y entre la primera y Brasil, el latinoamericanismo como opción cultural y como decisión geopolítica, el panamericanismo en

22 Además de dirigir proyectos de investigación, animar workshops internacionales, y participar en dossiers de revistas especializadas sobre estos temas (ver los detalles de los mismos en la introducción), organicé en 2019 el Grupo Interuniversitario de Estudios sobre Diplomacias y Culturas (GIEDyC), que nuclea a especialistas de Argentina, Chile, México y España. 
tanto promesa o condena, entre otros temas. Con esta agenda de investigación, he dado cuenta de cómo las miradas sobre Estados Unidos no eran en absoluto homogéneas en el cambio de siglo, revisé cómo en el largo plazo se forjó una noción de "comunidad letrada hispanoamericana", y analicé las intervenciones de intelectuales de distintas latitudes de América Latina en un escenario de avance norteamericano, entre otras cuestiones. ${ }^{23}$

El segundo frente se articula en torno a preguntas en las que trabajé para repensar las dinámicas de invención de la identidad nacional argentina y atender lo que llamo "el lado B" de la mismas. Con esta imagen intento resumir una cuestión central: en los estudios históricos argentinos se han explorado de manera muy exigua las preguntas que en otras tradiciones historiográficas cuentan con décadas de despliegue. Me refiero, sobre todo, a cómo se ha construido la identidad nacional en competencia y confluencia con otras identidades nacionales de países limítrofes, del continente, o europeos. Están disponibles numerosos estudios sobre la invención de la nación "hacia adentro", que muestran cómo se desataron procesos que tuvieron a "los otros" internos — los inmigrantes, principalmente - como elemento de observación privilegiado para el planteo de reflexiones y el despliegue de políticas educativas, por mencionar algunos aspectos; ${ }^{24}$ sin embargo, no se ha explorado cómo se construyó la argentinidad "hacia afuera", en competencia con la chilenidad o la brasilidad, por mencionar algunas opciones de comparación continental. Para captar esas manifestaciones y posibilidades estudié el despliegue de trayectorias intelectuales en ámbitos de repercusión internacional, como Exposiciones Universales, Centenarios patrios, y otros eventos de dimensión internacional. Por medio de estas indagaciones pude reconstruir cómo se pensó y publicitó la Argentina en eventos de interacción entre países. ${ }^{25}$ En estos trabajos revisé, además, los espacios que desde afuera del país operaron como ámbitos para

23 Pueden verse los siguientes trabajos: Bruno, Paula, "España como caleidoscopio. Observaciones de intelectuales argentinos sobre la comunidad letrada hispanoamericana, siglo XIX", en Historia Contemporánea, núm. 63, 2020, pp. 385-418; Bruno, Paula, "Estados Unidos como caleidoscopio. Ensayo sobre las observaciones de viajeros y diplomáticos del fin de siglo", Revista Complutense de Historia de América, vol. 39, 2013, pp. 23-38; Bruno, Paula, "Un momento latinoamericano. Voces intelectuales entre la I Conferencia Panamericana y la Gran Guerra", en Ferrán Archilés y Maximiliano Fuentes (eds.), Ideas comprometidas. Los intelectuales y la política, Madrid, Akal, 57-77.

24 Véase: "Vida intelectual de la Argentina de fines del siglo xIX y comienzos del Xx. Un balance historiográfico", en PolHis. Revista Bibliográfica del Programa Interuniversitario de Historia Política, núm. 9, 2012, pp. 69-91.

25 Entre otros pueden verse Bruno, Paula, "Las derivas de Paul Groussac como articulador cultural. Entre exposiciones internacionales, celebraciones y eventos públicos, 1882-1911", Anuario IEHS, núm. 32, 2017, pp. 111-134; Bruno, Paula, "Martín García Mérou y su vida diplomática en Estados Unidos, 1896-1900 y 1901-1905”, en Revista de Historia de América, núm. 156, enero-junio de 2019, pp. 143-180. 
pensar y representar la Argentina - las legaciones tenían un rol central en esta tarea- y los materiales que se redactaban e imprimían especialmente para estas ocasiones - libros, álbumes costumbristas, folletos, handbooks.

El tercer núcleo de intereses que desarrollo enhebra los anteriores a partir del estudio de trayectorias de diplomáticos que permiten, a la vez, revisar los temas sugeridos y desentrañar otros más novedosos. ${ }^{26}$ Para partir de una descripción contundente - y obvia-: hombres y mujeres de la vida diplomática, por definición, fueron figuras que articularon, mediaron, tradujeron — en sentido literal y figurado. Es decir, sus propias acciones operaron como puentes entre geografías y repertorios de ideas y como bisagras no siempre visibles para rastrear contactos culturales, espacios de construcción y circulación de saberes, circuitos editoriales, entre otros aspectos. Pero se trata también de figuras especialmente interesantes para estudiar las dinámicas de la geopolítica en dos niveles interrelacionados: uno es el protocolar e institucionalizado; el otro es el que se desplegaba más allá de las legaciones, las epístolas e informes con membretes y los banquetes oficiales. En el primer nivel, los estudios de historia diplomática tradicional nos han mostrado de qué manera se pueden exponer los procesos que cristalizaron en tratados, alineamientos y confrontaciones; en el segundo nivel, en cambio quedan numerosos caminos por recorrer. En mis estudios sobre Martín García Mérou, Eduardo Wilde y Lucio Mansilla, entre otros, he puesto de relieve la porosidad que se genera entre lo que la bibliografía especializada llama la "diplomacia formal" y la "diplomacia informal" - las expresiones no son de mi preferencia, pero creo que continúan teniendo claridad descriptiva. ${ }^{27}$ Las zonas que aparecen entre un circuito estatal, protocolizado, supuestamente jerárquico, y otro ritmado por las relaciones personales, las decisiones particulares y las tramas de afinidad abren campos de preguntas de investigación nutritivas y claramente desestabilizantes de varios consensos historiográficos vigentes. En estas zonas, los casos que estudio son los de figuras que desarrollaban tareas diplomáticas y generaban conocimientos sobre los países en que habitaban. Todas las producciones escritas de estas figuras son ricas para dar cuenta de superposiciones entre funciones estatales y labores intelectuales. A su vez, es sugerente pensar figuras argentinas que desarrollaron sus tareas en otras geografías a la luz de figuras extranjeras que pasaron o se instalaron en Argentina. Ver las dos partes de una trama de este tipo, permite sacar conclusiones interesantes sobre las imágenes

26 Bruno, Paula, Martin García Mérou. Vida intelectual y diplomática en las Américas, Bernal, Editorial de la Universidad Nacional de Quilmes, 2018.

27 Bruno, Paula, "El servicio exterior y el cuerpo diplomático argentino en cuestión durante la segunda presidencia de Julio A. Roca (1898-1904)", trabajo en progreso. 
del país y sus relaciones internacionales. He puesto en juego esta posibilidad al estudiar la visita de Georges Clemenceau en el año 1910 a Argentina. ${ }^{28}$

Por último, me interesa puntualizar que para llevar adelante estas agendas de investigación, deviene central el ejercicio de poner en diálogo series de fuentes que, en general, se asumen como series paralelas y no se cruzan. Me refiero a archivos personales, fondos de legación y archivos de las misiones diplomáticas, intervenciones breves publicadas en prensa periódica y revistas, y obras de más largo aliento que devinieron volúmenes o tomos de colecciones. Desde mi perspectiva como investigadora, concretar el cruce de estas series es una oportunidad única para que surjan nuevos interrogantes y para combatir la ociosa tentación de buscar en las fuentes ilustraciones de un dato o reafirmaciones de nuestros prejuicios. ${ }^{29}$

\section{ReFLeXión de Ascensión Martínez RIaZA ${ }^{30}$}

Una de mis líneas de investigación de largo recorrido reconstruye las relaciones entre Perú y España desde el restablecimiento oficial de relaciones en 1879 hasta el final de la Guerra Civil española. No he seguido un único enfoque ni he priorizado una línea historiográfica, aunque me interesa la aproximación diplomática, política, social y cultural. Los márgenes no son tan precisos y ha sido el curso de la investigación el que ha permitido, a través de casos de análisis conectados, llegar a modelos que se puedan contrastar con otros en clave comparativa.

Han sido denominadores comunes de este recorrido: rastrear y calibrar en qué tiempos y situaciones de diplomacia y cultura convergieron, unas veces al margen de los circuitos formales y otras con su concurso; analizar cómo legaciones y consulados manejaron las iniciativas culturales como un instrumento más en el juego de las relaciones oficiales; pensar en qué medida y por qué razones para desempeñar puestos en legaciones y consulados los gobiernos acudieron a hombres de cultura que no necesariamente eran funcionarios de carrera, pero estaban bien relacionados y formaban parte de redes ya tendidas.

Bruno, Paula, "Georges Clemenceau en la Buenos Aires de 1910”, en Bruno, Paula (coord.), Visitas culturales en la Argentina, 1898-1936, Buenos Aires, Editorial de la Universidad Nacional de Quilmes, 2014.

29 Bruno, Paula, "Historia intelectual e historia de los intelectuales. Usos de las fuentes", Claudia Salomón Tarquini, Sandra Fernández, María de los Ángeles Lanzilotta y Paula Laguarda (eds.), El hilo de Ariadna. Propuestas metodológicas para para la investigación histórica, Buenos Aires, Prometeo, 2019, pp. 301-308.

30 Correo electrónico: amriaza@ghis.ucm.es. ORCID: https://orcid.org/0000-0001-8566-8381 
La plataforma que ofrecía el puesto de representación fue atalaya privilegiada para establecer e intensificar contactos de distinto sesgo ya en interés propio o del país al que representaban. Identificar a esos agentes culturales, los circuitos en los que se integraron y detectar cómo siguiendo instrucciones de sus ministerios o por iniciativa propia intervinieron con dedicación y éxito variable en actividades y manifestaciones americanistas es una veta a explorar en la construcción de las relaciones bilaterales y transnacionales. Los ejemplos son numerosos y recorren el mapa de España e Hispanoamérica y los escenarios en los que se gestaron y concretaron muy diversos: tertulias, asociaciones, congresos, exposiciones o acontecimientos simbólicos. La prensa como objeto o como medio de circulación de información y debate fue espacio generalizado de convergencia.

La diplomacia cultural como área de estudio ha tomado carta de naturaleza y ha encontrado un lugar propio sobre la premisa compartida de que la cultura es un instrumento a tener en cuenta en las relaciones diplomáticas. Sin entrar en bucles teórico-metodológicos, se ha acudido a referentes historiográficos que han sido instrumentos útiles para avanzar y corroborar resultados. En lo que a mis investigaciones respecta, he incorporado herramientas de los estudios biográficos y los análisis de redes intelectuales, así como otras sugerencias en relación con la naturaleza y el alcance de las transferencias culturales

Los hitos de investigación que han jalonado mi trayectoria no son aleatorios, sino que responden a elecciones y decisiones que han ido componiendo un mapa, aún muy incompleto, de las relaciones entre el Perú y España. Una limitación de partida ha sido - y es - no contar con una historiografía de soporte sobre las relaciones exteriores de Perú en el tiempo largo; en cuanto a las relaciones entre Perú y España, sólo Fabián Novak trazó unas líneas genéricas en una publicación de 2001. ${ }^{31}$ Distinto es el caso español que cuenta con una profusa y renovada historiografía sobre la política exterior que incorpora como un elemento más las relaciones culturales.

La consulta sistemática de la documentación de los archivos especializados de Asuntos Exteriores de España y Relaciones Exteriores del Perú (política exterior, legaciones, consulados, personal) ha proporcionado información sobre temas que podían ser centrales. Algunos eran de entrada más estrictamente diplomáticos, como el arbitraje de la Corona en el conflicto Perú-Ecuador a comienzos del siglo xx, que sin embargo descubrió otras vías, como el interés de los gobiernos de la Restauración por hacer del arbitraje una cuestión de prestigio y acercamiento, o cómo se movieron los comisionados de los dos países más allá de su estricta misión. Acompañó a la del Perú, José Santos Chocano, un personaje controvertido que se involucró en asuntos turbios

31 Novak, Fabian, Las relaciones entre el Perú y España (1821-2000), Lima, Fondo Editorial PUCP, 2001. 
durante su estancia y que formó parte de una amplia red transnacional con aliados y detractores, y fue Comisionado Regio Ramón Menéndez y Pidal, reconocido en el medio cultural y académico hispanista.

Un recorrido general llevó a fijar la atención en la década de 1920 en que por razones políticas y culturales mantuvieron relaciones intensas dos regímenes autoritarios, los de Augusto Leguía y Miguel Primo de Rivera, que capitalizaron manifestaciones simbólicas como los Centenarios de la Independencia y Ayacucho y la Exposición Iberoamericana de Sevilla, acompañando el protocolo con un discurso hispanista en el que se reconocían como hija y Madre Patria, receptora y generadora de valores comunes de religión, lengua y otros atributos de la raza.

En un escenario jalonado de grandes silencios, a modo de balance se podrían avanzar algunas consideraciones. En la esfera de la diplomacia se ha observado que en las legaciones la representación española en Perú fue más profesional (carrera diplomática) y la información que los ministros de distinto rango trasladaban al Ministerio fue más prolija, prestando atención a la situación interna del país y a la de los españoles residentes en la República. En el caso de Perú, hasta la década de 1920, los representantes cambiaban con frecuencia bien por razones privadas, falta de financiación o por no haber asuntos de calado de que ocuparse. En ambos lados se registran sagas familiares, caso de los españoles Ojeda en Lima o de los peruanos Osma y Leguía en Madrid.

La presencia de hombres de cultura fue puntual pero significativa. En la legación de España durante la Segunda República un diplomático político, Antonio Jaén y Morente, dio un vuelco a los temas priorizando lo social y cultural. $^{32}$ En la de Perú, también durante la Segunda República, Pablo Abril de Vivero fue secretario y editor en Madrid de la revista Bolívar, que entra de lleno en los parámetros de ser soporte de redes intelectuales y culturales. Una línea pendiente de grandes posibilidades para entender la conformación de redes transnacionales es la de hacer un seguimiento de diplomáticos que recorrieron distintos países de Iberoamérica y España.

Los consulados se significaron como instituciones clave por cuanto se ocupaban, además del comercio y de velar por los intereses de sus nacionales, de asuntos que las legaciones no siempre atendían como la propaganda y representación. La tendencia fue que frecuentemente desempeñaron el puesto hombres de prestigio, bien relacionados, que no necesariamente eran funcionarios de carrera ni oriundos de los países representados.

32 Martínez Riaza, Ascensión, "El desarraigo inevitable. Jaén y Morente, un intelectual republicano español en el exilio americano", en Almudena Delgado Larios (coord.), Conflictos y cicatrices: fronteras y migraciones en el mundo hispánico, Madrid, Dickinson, 2014, pp. 321-339. 
Como caso de estudio y con el soporte de documentación oficial y privada, pude componer una monografía sobre Antonio Pinilla Rambaud, al frente del Consulado de España en Lima desde 1918 hasta 1939, un período de tiempo excepcionalmente largo en un destino de representación oficial que le permitió, mientras se sucedían cinco ministros, dar continuidad a asuntos y relaciones. Conoció la situación de los españoles en Perú y se relacionó con la élite de la colonia potenciando asociaciones que se convirtieron en potentes redes internas y nexos con el poder social y económico del Perú (Casino Español, Sociedad Española de Beneficencia de Lima y Cámara Oficial Española de Comercio del Perú). Arraigó en la sociedad peruana por matrimonio y se integró en circuitos culturales contándose entre los fundadores de la revista cultural Mercurio Peruano junto a Víctor Andrés Belaunde. Entendió la cultura como vehículo para afirmar la presencia de España en el Perú desde la formación hispanista adquirida en la Institución Libre de Enseñanza donde se formó con Rafael Altamira y Eduardo Barnés.

Pinilla escribió. Se han podido consultar 28 referencias entre libros, folletos y artículos. Su obra constituye un cuerpo documental de primer orden para aproximarse no sólo distintos ámbitos de las relaciones bilaterales, sino también a la sociedad, la economía y la cultura peruanas. Sobresalen las siguientes tres referencias: El Libro Español en el Perú (1922), El Comercio hispanoperuano: su realidad y sus posibilidades (1924), y el Informe sobre comunicaciones marítimas, respondiendo a un cuestionario remitido por la Asociación de Españoles de Ultramar (1935). Tienen en común el ser respuesta a demandas de instancias culturales españolas de carácter oficial, una de la Monarquía, otra de la Dictadura de Primo de Rivera y la tercera de la Segunda República.

En política basculó de posición transitando de liberal moderado a "nacional" y falangista. Acató la autoridad de los distintos gobiernos que se sucedieron en España y fue especialmente complaciente con la dictadura de Primo de Rivera, porque, como Leguía en el Perú y Mussolini en Italia, defendía el orden y progreso. Se alineó cuando se produjo la sublevación militar el 18 julio de 1936. Presentó su dimisión al gobierno de la República y siguió ejerciendo de cónsul, ya leal a la Junta de Burgos y con el consenso tácito del gobierno peruano de Benavides, mientras los asuntos de la República eran gestionados por el gobierno de México. Se afilió a la Falange y publicó, en 1938, "El Himno de la Falange Española de las JONS" que meses después editó como folleto, Glosa al Himno de Falange. ${ }^{33}$

33 Martínez Riaza, Ascensión, En el Perú y al servicio de España. La trayectoria del cónsul Antonio Pinilla Rambaud, 1918-1939, Lima, Instituto Riva Agüero, 2008; "Al servicio de la República. La acción exterior de España en el Perú, 1931-1936”, Revista de Indias, vol. LXVII, núm. 240, Madrid, CSIC, septiembre-diciembre, 2007, pp. 713-762. 
¿Y la contraparte del Perú en España? El acceso a la documentación del Ministerio de Relaciones Exteriores ha sido la base para entrar en los consulados de las principales ciudades en una casuística que poco tiene que ver con el ejemplo de Pinilla. Barcelona era centro económico y cultural de la España del primer tercio del siglo Xx. Y en el Consulado del Perú ejercieron —en los períodos 1902-1904 y 1918-1919 respectivamente - dos hombres de cultura, y además políticos, ampliamente reconocidos, Clemente Palma y José Gálvez Barrenechea. En ambos casos se ha tenido acceso a correspondencia privada (de Clemente Palma con su padre Ricardo Palma, y de José Gálvez con José de la Riva Agüero) que descubrió "el otro lado" de la experiencia consular. Debieron su nombramiento a sus vinculaciones con el poder establecido de cuya trama formaban parte. Les interesaba el destino por razones económicas sin olvidar el prestigio y reconocimiento que el puesto llevaba aparejado y además ambos querían publicar en editoriales españolas.

En una valoración global y en relación con sus obligaciones consulares se puede concluir que Palma se mantuvo bajo mínimos, limitándose a hacer escuetos diagnósticos sobre el estado de las exportaciones y a lamentar la ausencia de una línea de navegación directa. Sí se implicó en el encargo del Gobierno de promover una inmigración selectiva y retomó sus argumentos darwinistas de El Porvenir de las razas en el Perú (1897) sobre la necesidad de incentivar la llegada de vascos antes que catalanes. Gálvez, sin experiencia previa, se volcó en la variable económica, elaborando informes minuciosos sobre las exportaciones e importaciones y negociando con las líneas de navegación que operaban en Barcelona para conseguir que sus buques llegaran directamente a los puertos del Perú. Centrado en sus asuntos personales Palma no se relacionó con los círculos culturales. Polarizó su atención en hacer un seguimiento de la edición de la obra de su padre y en conseguir que Miguel de Unamuno prologara la edición de sus Cuentos Malévolos. Gálvez publicó asiduamente en periódicos y revistas españoles, tanto para divulgar sus trabajos como para hacer propaganda del Perú, particularmente en relación con el litigio que mantenía con Chile. Pero en la correspondencia con José de la Riva Agüero se lamentó de no tener tiempo para escribir ni para relacionarse con afines. Paradójicamente fueron dos hombres de cultura que no participaron ni incentivaron manifestaciones culturales. ${ }^{34}$

Diplomacia y cultura se proyectaron en un amplio abanico de manifestaciones que traspasaron los límites de las relaciones bilaterales. El

34 Martínez Riaza, Ascensión, “Agentes culturales y "hombres prácticos”. Clemente Palma y José Gálvez Barrenechea en el Consulado del Perú en Barcelona (1900-1919)”, en Pilar Cagiao Vila (ed.), Donde la política no alcanza. El reto de diplomáticos y agentes culturales en la renovación de las relaciones entre España y América, 1880-1939, Madrid, Iberoamericana-Vervuert, 2018, pp. 111-158. 
Perú asistió oficialmente al IV Centenario del Descubrimiento volcándose en la Exposición Histórico Americana, y con un pico de mayor intensidad en la Exposición Iberoamericana de Sevilla de 1929. En el Oncenio de Leguía fueron los centenarios de la Independencia y de Ayacucho los que permiten pulsar el interés de los gobiernos de ambos países por participar en ambas celebraciones.

En el IV Centenario la representación diplomática, destacada para la ocasión, se ocupó de que la presencia del Perú estuviera a la altura del resto de las repúblicas canalizando la exhibición de objetos arqueológicos, que estuvo plagada de problemas de traslado y cuantía y valor de las piezas. El comisionado oficial Ricardo Palma asistió a las ceremonias ineludibles sin participar en el rosario de congresos y otros actos que se sucedieron. Se centró en lo que eran sus intereses, la incorporación de americanismos al Diccionario de la Real Academia de la Lengua y la publicación de sus Tradiciones Peruanas.

En el Perú el régimen autoritario de Leguía capitalizó la oportunidad de los centenarios para hacer de Lima centro de atracción internacional y mostrar sus logros modernizadores. Se celebraba la independencia de España y la última derrota de España. La literatura se ha ocupado profusamente de diferentes variables, en especial del Centenario de la Independencia. En ese contexto he tratado la participación española argumentando que tanto en el Centenario de la Independencia como en el de Ayacucho hubo un notable desequilibrio entre el interés mostrado por Leguía por dar a España un lugar destacado en el protocolo y ceremonias y la respuesta distante de la antigua metrópoli. Los centenarios no fueron una preocupación especial de los gobiernos de los últimos años de la Restauración y la Dictadura de Primo de Rivera (1923-1930). Ni siquiera concitó atención especial entre los hombres de cultura e intelectuales vinculados a las dos corrientes del americanismo, el panhispanismo y el hispanoamericanismo progresista. La representación diplomática en Lima, Emilio Ojeda en 1921 y sus hijos Jaime y Gonzalo en 1924 se empleó para que los gobiernos enviaran a misiones a la altura del rango de Madre Patria que Leguía reconocía en los discursos oficiales. Al Centenario de la independencia asistió una embajada de hombres que no ocupaban altos puestos en la política y apenas sobresalieron. En 1924 se repitió la invitación de Leguía al Rey y en su caso a una misión de alto nivel. Pero los responsables políticos declinaron la invitación aduciendo que ya habían cumplido en 1921, cuando en realidad, y así aparece en la documentación, no podían asistir a la celebración de lo que había sido una "desgraciada batalla". Como alternativa se invitó a prestigiosos hombres de cultura que declinaron excepto Vicente Gay, Julio Camba y Luis Jiménez Asúa cuya intervención he seguido en profundidad. ${ }^{35}$ No se oculta

35 Martínez Riaza, Ascensión, "Las cicatrices de Ayacucho". España en la celebración de un centenario Hispanoamericano”, Anuario IEHS, vol. 32, núm. 1, 2017, pp. 179-204. 
que la documentación oficial silencia y también distorsiona realidades y que indefectiblemente ha de ser contrastada con otras fuentes no siempre accesibles, como la correspondencia de y sobre los implicados. En cualquier caso, entiendo que el paso de la investigación individual a la emprendida por grupos que cruzan e intercambian, incluso desacuerdos, es sin duda uno de los haberes de este tiempo.

\section{Reflexión de Alexandra Pita González ${ }^{36}$}

Estudiar las relaciones entre vida cultural y diplomacia es apasionante. Para explicar los motivos por los que me adentré en este tema, me sirve contar una anécdota particular. Estaba en el Archivo de Historia Social de Ámsterdam buscando información sobre asociaciones anarquistas relacionadas con proyectos educativos y me topé con documentos titulados "Cooperación Intelectual", en los que aparecían mencionados muchos intelectuales latinoamericanos. Eso llamó mi atención y en los siguientes archivos que visité, busqué más información. Empecé así a armar un gran rompecabezas que tenía que ver - y no- , con la historia intelectual que había estado estudiando hasta ese momento. Todos los actores coincidían en la misma temporalidad: el período de entreguerras; a veces incluso aparecían en las mismas revistas culturales que estudiaba como autores de artículos, pero a diferencia de los otros intelectuales, éstos - los que participaban de Cooperación - tenían rasgos distintos. Comencé por intentar entender qué significaba la diplomacia cultural para este grupo de actores latinoamericanos. ${ }^{37}$

Pero lo más importante, a nivel de aprendizaje, fue entender a estos intelectuales que actuaban en ámbitos oficiales recibiendo por ello críticas de quienes afirmaban que deambulaban por espacios de "intereses imperialistas", ya sea propiciados desde Washington (Unión Panamericana) o desde Ginebra (Sociedad de Naciones). Entendí que estos actores conocían ambos mundos a la perfección y podían convivir en dos redes que, por momentos, coincidían, pero en otros chocaban. Por ello, al pensar retrospectivamente sobre el origen de este tipo de actor, surgió la idea de plantear la necesidad de reflexionar sobre los intelectuales/diplomáticos, no sólo en el siglo xx, sino también en el siglo $\mathrm{XIX}^{38}$

36 Correo electrónico: apitag@ucol.mx. ORCID: https://orcid.org/0000-0003-1211-0365

37 De ello surgió un capítulo de libro: Pita, Alexandra, "La diplomacia mexicana de entreguerras: una aproximación al debate", en Fabián Herrera León, Diplomacia oficiosa, representaciones y redes extraoficiales en la historia de América Latina: un homenaje a la trayectoria académica de Salvador E. Morales Pérez, Morelia, IIH, Morelia, Michoacán, México, 2015, pp. 107-130.

38 Junto con Carlos Marichal coordinamos un dossier temático muy interesante en la Revista 
De este modo, la relación entre vida cultural y diplomacia comenzó a ser un tema de mi interés. Me enfoqué en reconstruir la relación de México con el ámbito de la llamada Cooperación Intelectual, sin perder de vista el contexto regional que imponían los otros países, fundamentalmente, Estados Unidos. ${ }^{39}$ Tras detectar a los actores principales me centré en Alfonso Reyes porque jugó un papel fundamental como mediador en todos los sentidos y direcciones: entre intelectuales latinoamericanos y europeos, entre cancillerías (y al interior de cada una de ellas), entre el ámbito intelectual y el diplomático, entre redes intelectuales. Esto me permitió redescubrirlo como intelectual a través de la función diplomática, pero también descubrir que el ámbito de la historia de las relaciones internacionales era sumamente complejo y, a la vez, interesante. Planteaba, entonces, numerosos desafíos. Esto me generó preguntas como las siguientes: ¿quién era Alfonso Reyes cuando actuaba como diplomático?, ¿de qué manera puso sus redes intelectuales al servicio de sus labores diplomáticas?, ¿en qué sentido fue distinta su actuación a la de otros que no provenían del ámbito intelectual? ${ }^{40}$

Estas preguntas me condujeron a reflexionar sobre la confluencia en temas como éste e historia política, intelectual y diplomática. Es difícil hoy en día hablar de una marcada diferencia entre estas líneas porque todas han sufrido varias reinterpretaciones. Sin embargo, creo que la que ha realizado un cambio más radical ha sido la historia diplomática al ser revisada $-\mathrm{y}$ rebasada - por la historia cultural de las relaciones internacionales. Desde que se produjo este giro, no se escribe como antes una historia apologética y de bronce de personajes ilustres que pasaron por cancillería mencionando sus cualidades y virtudes. Se piensa, en cambio, en actores que por distintos motivos y desde distintos ángulos estuvieron relacionados de una u otra manera

de Historia de América y escribimos un artículo que sirvió de estudio introductorio para plantear algunos aspectos a tener en cuenta al pensar en los intelectuales/diplomáticos. Véase, Marichal, Carlos y Pita, Alexandra, "Algunas reflexiones sobre la historia de los intelectuales/diplomáticos", Revista de Historia de América, núm. 156, enero-junio, 2019, pp. 97-123. Véase la Introducción para detalles de este dossier.

39 De esta experiencia surgió el libro Pita, Alexandra, Educar para la paz. México y la Cooperación Intelectual Internacional, 1922-1948, México, Secretaría de Relaciones Exteriores, Universidad de Colima, 2014.

40 Pita González, Alexandra, "América (Latina) en París. Mistral, Reyes y Torres Bodet en la colección iberoamericana, 1927-1940”, en Fabián Herrera León y Yannick Wehrli (coords.), América Latina y el internacionalismo ginebrino de entreguerras: resonancias e implicaciones, México, Dirección General del Acervo Histórico Diplomático, 2019, pp. 241276; Pita, Alexandra, "La colección de etnografía e historia de América y el embajador Roberto Levillier en México, 1934-1939”, Historia Mexicana, vol. LXVIII, núm. 4, abril-junio 2019, pp. 1697-1742; Pita, Alexandra, "El Código de la Paz y la trama del panamericanismo en la década de 1930", Estudos Ibero Americanos, vol. 46, núm. 3, septiembre-diciembre, 2020, pp. 1-16. 
con las relaciones entre los países, pero que además tenían otras facetas en su vida, es decir, eran parte de varios espacios. Estas relaciones exceden el mirar sólo las cancillerías. Además, al involucrar el soft power como una dimensión fundamental y explorar la diplomacia cultural se abrió un mundo de posibilidades a estudiar. Fue necesario también que se pusieran en tela de juicio una serie de preceptos teóricos para salir del hermetismo oficial con el cual se escribía la historia diplomática. Para ello fue indispensable que cada investigador e investigadora echara mano a su bagaje académico y alimentara de nuevas miradas sus investigaciones.

En mi caso, que provenía de la historia intelectual, pude conjugar perspectivas de manera natural e intuitiva porque estudié actores que fueron intelectuales y diplomáticos. Me centré además en un espacio en el cual esta conjunción fue idónea, como fue la Cooperación Intelectual durante el período de entreguerras. Este marco de referencia me permitió explorar un ámbito oficial de un organismo internacional con la mirada crítica de la historia intelectual, que sitúa el texto en su contexto, y analiza las tensiones y discusiones al interior de un grupo, más que los momentos de acuerdo. Por poner un ejemplo, tras reconstruir la serie de conferencias y reuniones, y entender las agendas a discutir, me enfoqué más en los debates de los puntos que no pudieron ser acordados en las resoluciones finales. Es ahí donde se puede entender, desde mi perspectiva, además, la injerencia de estos actores, sus percepciones de peligros y necesidades de alianzas y cambios de rumbo en las negociaciones.

En este sentido, es importante mencionar la ventaja que he tenido al utilizar fuentes primarias resguardas en archivos diplomáticos. La primera vez que fui al Archivo Diplomático Genaro Estrada, en la Ciudad de México, pensé que no regresaría jamás. Acostumbrada a trabajar con correspondencia, revistas, periódicos y libros, sentía que los expedientes diplomáticos eran aburridos y reiterativos, que contenían poca información y que ésta generalmente se centraba en datos formales, pero vacíos de contenido. Pero como soy tenaz y tenía que aprobar una materia que me gustaba mucho sobre las Conferencias Panamericanas, me sumergí en la Conferencia de Río y comencé a entender el valor de la selección de los artículos de prensa que enviaban los delegados, las cartas confidenciales antes, durante y después de cada evento; los telegramas de último momento (algunos cifrados) para modificar rápidamente el rumbo de algo. Es decir, fui descubriendo a los actores y poco a poco entendía que casi nada tenían que ver con mi primera mirada que los ubicaba en un lugar de poca acción. ${ }^{41}$

41 La visita al archivo fue impulsada por el profesor Carlos Marichal en el marco de un curso sobre historia de las relaciones internacionales en el Doctorado de Historia de El Colegio de México. De esta experiencia surgió un libro muy interesante donde se analizan las conferencias panamericanas. Allí escribí un texto en coautoría: Lara María de Toledo Mancuso, Lara 
Cuando pude acceder al archivo de la unEsco en París (que había sido de Cooperación Intelectual), quedé asombrada en todos los sentidos. En primer lugar, me emocionó que las cajas no hayan sido reclasificadas y que lo que se consultaba era más que un índice, un inventario, de lo que se entregó una vez que el emprendimiento se transformó en la unESCO a mediados de la década de 1940. Además, revisar cientos de documentos, me hacía dimensionar la labor de numerosas personas involucradas en distintas pequeñas comisiones para llevar adelante proyectos. Esta experiencia cambió mi mirada sobre el objeto de estudio. Cooperación Intelectual no era un intento fallido de un grupo de idealistas que no pudo generar una consciencia favorable a la paz para evitar la guerra. Había sido, en cambio, un macro emprendimiento en el cual los intelectuales tuvieron que romper sus fronteras nacionales para entender el significado de lo internacional.

Esto no significa que olvidé mis antiguos documentos. En realidad, ha sido de gran utilidad el combinar ambos porque las cartas que guardan los archivos privados de estos intelectuales/diplomáticos, permiten entender el conflicto, el enojo, la tristeza y la sensación de fracaso. Permiten otorgar a los archivos diplomáticos una dimensión humana, que es evidentemente, relevante. Sin embargo, aun esas cartas tenían que ser leídas en otra clave. Recuerdo la primera vez que vi la correspondencia entre Alfonso Reyes y Genaro Estrada, no presté atención a los subrayados en el encabezado donde marcaba si era personal, confidencial, oficial o ultra confidencial. Tras darme cuenta, tuve que releer todo de nuevo para entenderlas realmente. Otro tipo de fuente que analizaba antes y me fue de gran utilidad son las memorias, los diarios, y las obras que publicaron estos actores durante y después de su actuación en ámbitos diplomáticos.

Por todo esto, creo que las relaciones internacionales se han nutrido del aporte de las otras líneas de historia. El proceso se puede ver también a la inversa. No creo que esta influencia sea visible aún, porque falta mucho por discutir y, en general, investigadores e investigadoras somos un poco reacios a salir de nuestra zona de confort (un tema, un período, un personaje) para reflexionar sobre lo más general, pero a la vez esencial: es decir: qué aprendimos de un estudio de caso y de qué manera esto se vincula con lo que está haciendo otro. Lamentablemente, estas son preguntas que no tienen cabida en los congresos a los que acudimos con frecuencia.

María, González Tejeda, Gloria y Pita, Alexandra, "III Conferencia Panamericana (Río de Janeiro, 1906)", en Carlos Marichal (coord.), México y las Conferencias Panamericanas, 1889-1938. Antecedentes de la globalización, Ciudad de México, Secretaría de Relaciones Exteriores, 2002, pp. 79-98. 